\title{
Gene transcription of neuroglobin is upregulated by hypoxia and anoxia in the brain of the anoxia-tolerant turtle Trachemys scripta
}

\author{
Sarah L. Milton ${ }^{1, *}$, Gauri Nayak ${ }^{1}$, Peter L. Lutz ${ }^{1} \&$ Howard M. Prentice $^{2}$ \\ ${ }^{1}$ Department of Biological Sciences SC 281, Florida Atlantic University, 777 Glades Road, Boca Raton, FL, \\ 33431, USA; ${ }^{2}$ Department of Biomedical Sciences, Florida Atlantic University, 777 Glades Road, Boca Raton, \\ FL, 33431, USA
}

Received 15 February 2006; accepted 21 March 2006

(c) 2006 National Science Council, Taipei

Key words: anoxia, hypoxia, neuroglobin, Trachemys scripta

\section{Summary}

Neuroglobin is a heme protein expressed in the vertebrate brain in mammals, fishes, and birds. The physiological role of neuroglobin is not completely understood but possibilities include serving as an intracellular oxygen-carrier or oxygen-sensor, as a terminal oxidase to regenerate $\mathrm{NAD}^{+}$under anaerobic conditions, or involvement in NO or ROS metabolism. As the vertebrate nervous system is particularly sensitive to hypoxia, an intracellular protein that helps sustain cellular respiration would aid hypoxic survival. However, the regulation of Neuroglobin $(\mathrm{Ngb})$ under conditions of varying oxygen is controversial. This study examines the regulation of $\mathrm{Ngb}$ in an anoxia-tolerant vertebrate under conditions of hypoxia and anoxia. The freshwater turtle Trachemys scripta can withstand complete anoxia for days, and adaptations that permit neuronal survival have been extensively examined. Turtle neuroglobin specific primers were employed in RT-PCR for determining the regulation of neuroglobin mRNA expression in turtles placed in normoxia, hypoxia $(4 \mathrm{~h})$, anoxia $(1$ and $4 \mathrm{~h}$ ), and anoxia-reoxygenation. Whole brain expression of neuroglobin is strongly upregulated by hypoxia and post-anoxic-reoxygenation in $T$. scripta, with a lesser degree of upregulation at 1 and $4 \mathrm{~h}$ anoxia. Our data implicate neurglobin in mediating brain anoxic survival.

\section{Introduction}

Neurons are generally viewed as among the most anoxia sensitive of all cells, though recent studies have shown a wide variation in the capacity of neurons to tolerate hypoxia, reflective of their function and the degree of hypoxia normally encountered. Even the most vulnerable neurons are not defenseless, and the most tolerant are able to withstand extreme periods of complete anoxia and recover fully when oxygen becomes available [1]. The fate of hypoxic or ischemic neurons

*To whom correspondence should be addressed. Fax: $+561-$ 297-2749; E-mail: smilton@fau.edu depends upon both physiological and molecular events, with pro-survival and apoptotic pathways competing at the transcriptional and posttranscriptional level. These events include the upregulation of various pathways that increase anaerobic metabolism or oxygen delivery, including erythropoietin [2], vascular endothelial growth factor [3] and heat shock proteins [4]. At the physiological level, pro-survival pathways include the opening of ATP-regulated potassium channels [5], and increases in inhibitory neurotransmitters including GABA [6], and adenosine [7, 8].

Not all vertebrate brains, however, are equally sensitive to hypoxia. Freshwater turtles of the genus Trachemys are true facultative anaerobes, 
able to survive from up to $48 \mathrm{~h}$ at room temperature to months (during winter hibernation) in the total absence of oxygen [9]. Trachemys scripta has been the subject of extensive research into the adaptations that permit neuronal survival without oxygen [1]; the turtle brain is able to decrease its metabolic rate to approximately $10-15 \%$ of basal, such that energy utilization is matched to anaerobic energy production. By preventing an energy deficit, the turtle brain avoids the catastrophic drop in ATP levels which, in mammalian neurons, results in the breakdown of cellular ion homeostasis, release of excitatory neurotransmitters, and excitotoxic cellular death [1]. To decrease neuronal energy requirements, Trachemys decreases membrane ion permeability ("channel arrest"), inhibits the release of excitatory neurotransmitters such as dopamine [10] and glutamate [11], increases the release of inhibitory compounds including adenosine [12] and GABA [13], and decreases electrical activity [14]. In terms of molecular changes, organ-level alterations of MAP kinases, ERK, and JNK have been reported [15], while work in our lab has shown increased expression of heat shock proteins [16] and the downregulation of $\mathrm{Kv}$ channel transcription [17]; alterations in many of these molecular factors have been linked to hypoxic/ischemic survival in the mammalian CNS. Such extended anoxic survival time is not a matter of ectothermy, as other reptiles survive only $20-30 \mathrm{~min}$ without oxygen [18] and do not exhibit the same neurological adaptations that permit true anoxic tolerance [19].

As the CNS in most vertebrates, however, is particularly sensitive to $\mathrm{O}_{2}$ lack, the increased expression of a protein that helps to sustain cellular respiration could increase neuronal survival under the low oxygen conditions of hypoxia or ischemia. Neuroglobin (Ngb), a recently discovered heme protein of the CNS, is a highly conserved protein able to bind oxygen reversibly. First reported in mouse brain [20], Ngb has since been identified as well in fish, amphibians, and birds [21], pointing to its likely presence in all vertebrates. Globins are usually considered either oxygen transporter or $\mathrm{O}_{2}$ storage proteins, therefore a likely role for $\mathrm{Ngb}$ is as a "neuronal myoglobin" transferring oxygen to the mitochondrial respiratory chain in the brain and retina [21]. Other potential roles include acting as a terminal oxidase that regenerates $\mathrm{NAD}^{+}$under anaerobic conditions [22-24], aiding in the detoxification of reactive oxygen species, or as a sensor to detect cellular oxygen concentrations.

To date, however, it is unclear if $\mathrm{Ngb}$ is regulated under varying $\mathrm{O}_{2}$ levels, with some studies reporting increased expression of $\mathrm{Ngb}$ mRNA and protein in cerebral tissue culture after $24 \mathrm{~h}$ anoxia-reperfusion [25], while other investigations [26] did not find increased expression in hypoxic $\left(10 \% \mathrm{O}_{2}\right)$ mice in vivo. These conflicting results, however, could indicate that $\mathrm{Ngb}$ is involved only during acute hypoxia. Increased levels of $\mathrm{Ngb}$ have been shown to protect against hypoxic/ischemic injury in both cultured neurons [25] and in an experimental stroke model in rats [27]. Because of the exquisite sensitivity of the mammalian brain to severe hypoxia/anoxia, however, investigation of the regulation of $\mathrm{Ngb}$ under such conditions is difficult. The brain of the anoxia- tolerant turtle offers a unique model to identify strategies to enhance the survival of neurons vulnerable to hypoxia/reoxygenation stress, while providing a means to separate protective responses from the mammalian mixture of adaptive and pathological responses [28].

In this study, we examined the in vivo expression of $\mathrm{Ngb}$ mRNA using RT-PCR in whole T. scripta brains in hypoxia $\left(5 \% \mathrm{O}_{2}\right)$, short term $(1 \mathrm{~h})$ and long-term (4 h) anoxia, and upon anoxia-reoxygenation.

\section{Material and methods}

All experiments were conducted with the approval of Florida Atlantic University Institutional Animal Care and Use Committee. Freshwater turtles (Trachemys scripta) weighing 300-500 g obtained from commercial suppliers (Lemberger Reptiles, Oshkosh, WI) were maintained at room temperature $\left(22-23{ }^{\circ} \mathrm{C}\right)$ in freshwater aquaria on a $12 \mathrm{~h}$ light/dark cycle. Animals were fed $3 \times$ weekly to satiation on commercial turtle food.

\section{Tissue preparation}

Five experimental sets of $n=5$ included normoxic controls, anoxic animals exposed to 1 or $4 \mathrm{~h}$ anoxia, $4 \mathrm{~h}$ anoxia/ $4 \mathrm{~h}$ normoxic recovery, and $4 \mathrm{~h}$ hypoxia $\left(5 \% \mathrm{O}_{2}\right)$. For anoxic exposure, animals were individually placed in sealed $2 \mathrm{~L}$ plastic chambers at room temperature $\left(23^{\circ} \mathrm{C}\right)$ under 
99.99\% $\quad \mathrm{N}_{2} \quad$ (positive pressure flow-through, County Welding, Pompano Beach, FL). Normoxic controls were utilized directly from the aquaria. Hypoxic animals were placed in individual open holding boxes in a hypoxia chamber (Sheldon Manufacturing, Cornelius, OR) under $5 \% \mathrm{O}_{2}$ for $4 \mathrm{~h}$. Chamber $\mathrm{PO}_{2}$ was determined hourly to ascertain $\mathrm{O}_{2}$ levels (Cameron Instrument Company, Port Aransas, TX).

Animals were sacrificed by cervical separation and the brains removed into liquid nitrogen in less than 2 min.

\section{$R T-P C R$}

Total RNA was extracted using the TRIzol reagent (Life Technologies, Grand Island, NY) according to the manufacturer's protocol and RNA was subjected to treatment with DNAse I to eliminate DNA contamination. Complementary DNA was synthesized from total RNA using primers specific for neuroglobin and actin, respectively. The PCR using Taq polymerase comprised denaturation for $7 \mathrm{~min}$, $94^{\circ} \mathrm{C}$, PCR: 40 cycles $(\mathrm{Ngb})\left(1 \mathrm{~min}, 94{ }^{\circ} \mathrm{C} ; 45 \mathrm{~s}, 59{ }^{\circ} \mathrm{C} ; 1.0 \mathrm{~min}, 72{ }^{\circ} \mathrm{C}\right)$ followed by elongation: $10 \mathrm{~min}, 72^{\circ} \mathrm{C}$ or 30 cycles (actin) $\left(1 \min 94^{\circ} \mathrm{C} ; 45 \mathrm{~s}, 55^{\circ} \mathrm{C} ; 1.5 \min 72^{\circ} \mathrm{C}\right)$ followed by elongation: $10 \mathrm{~min} 72^{\circ} \mathrm{C}$.

Primers specific to turtle neuroglobin cDNA were designed from a partial cDNA sequence that was obtained previously by RT-PCR analysis of turtle brain mRNA using degenerate primers homologous to neuroglobin sequences from mouse and zebrafish. The primers employed for PCR were the following: turtle brain specific neuroglobin primers: 5'-GTTGTTTGATCTGGACCCTGAC$3^{\prime}$ (forward) and 5'-TTGCCCAAGTTGGAGA
GATATT-3' (reverse); actin primers: 5'-CAC CAACTGGGACGACATGG-3' (forward) and 5'-GTCGGCCAGCTCGTAGCTCT-3' (reverse) (Table 1).

PCR products were separated by gel electrophoresis, visualized by ethidium bromide and photographed using a digital camera for quantification using National Institute of Health Image $\mathbf{J}$ 1.60 software.

For semi-quantitative measurement of neuroglobin transcript levels, RT-PCR signal intensities were calculated as a ratio of levels of PCR products amplified from turtle actin cDNAs. Data are expressed as percent increase above normoxic control.

Statistical analysis: data were analyzed by ANOVA (Dunn's Multiple Comparison test; $p<0.05$ was considered to be significant).

\section{Results}

To establish whether neuroglobin transcription was influenced by oxygen availability, we measured levels of neuroglobin mRNA expression in brain from normoxic turtles and turtles subjected to $4 \mathrm{~h}$ hypoxia at $5 \% \mathrm{O}_{2}, 1 \mathrm{~h}$ anoxia, $4 \mathrm{~h}$ anoxia, and $4 \mathrm{~h}$ anoxia followed by $4 \mathrm{~h}$ reoxygenation. Levels of mRNA expression were normalized to actin mRNA control levels.

A clear upregulation of neuroglobin mRNA expression (3.5-fold increase, $p<0.01$ ) was seen at $4 \mathrm{~h}$ hypoxia whereas a more modest but progressive increase was found in 1 and $4 \mathrm{~h}$ anoxia reaching a 2.0-fold increase by $4 \mathrm{~h}$ anoxia $(p<0.05)$ (Figures 1 and 2$)$. On reoxygenation following $4 \mathrm{~h}$ anoxia high levels of neuroglobin

Table 1. Primer sequences and size of RT-PCR products.

\begin{tabular}{llll}
\hline Target gene & Predicted size $(\mathrm{bp})$ & Sense/Antisense & Location, nucleotides \\
\hline Neuroglobin & 193 & $5^{\prime}$-GTTGTTTGATCTGGACCCTGAC-3' & $368-389$ \\
& & $5^{\prime}$-TTGCCCAAGTTGGAGAGATATT-3' & $559-580$ \\
Actin & 505 & $5^{\prime}$-CACCAACTGGGACGACATGG-3' & $228-247$ \\
& & $5^{\prime}$-GTCGGCCAGCTCGTAGCTCT-3' & $713-732$ \\
\hline
\end{tabular}

The predicted product size and location of oligonucleotide binding sites for neuroglobin RT-PCR products are indicated. For neuroglobin RT- PCR products predicted size of product and location of oligonucleotide binding sites are based upon a partial cDNA sequence from turtle brain and the mouse coding sequence (Accession No. NM022414). For actin RT-PCR products predicted size and location of oligonucleotide binding sites are based on the salmon $\beta$-actin coding sequence (Accession No. AF309819). Primers for $\beta$-actin were homologous to both the salmon and human coding sequences. 

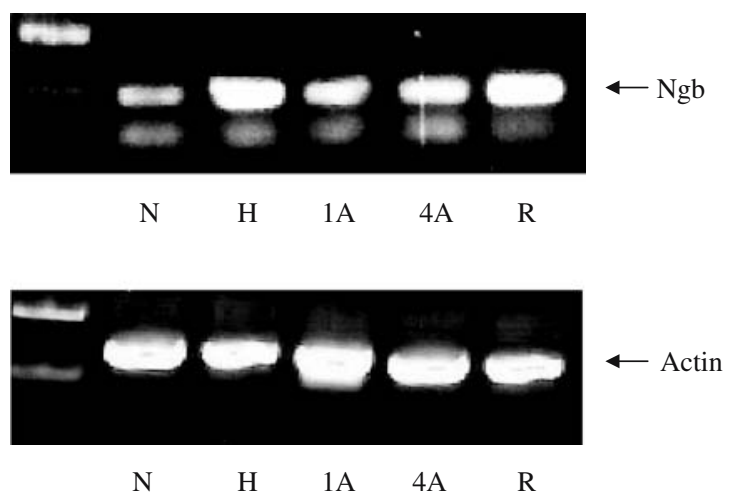

Figure 1. Representative gels showing increased neuroglobin transcription relative to actin controls in the T. scripta brain. Gels were visualized with ethidium bromide and digitally photographed for analysis. $\mathrm{N}=$ normoxia, $\mathrm{H}=4 \mathrm{~h}$ hypoxia, $1 \mathrm{~A}=1 \mathrm{~h}$ anoxia, $4 \mathrm{~A}=4 \mathrm{~h}$ anoxia, $\mathrm{R}=4 \mathrm{~h}$ anoxia $/ 4 \mathrm{~h}$ reoxygenation.

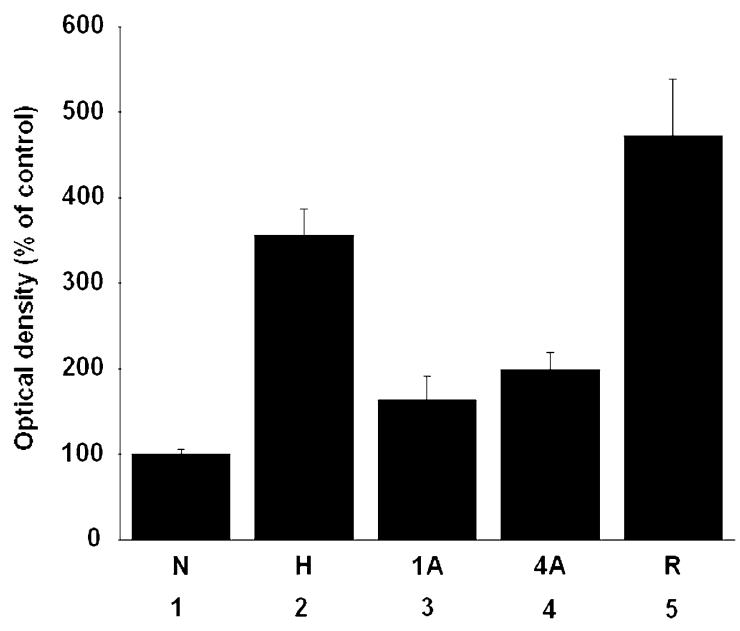

Figure 2. Changes in neuroglobin mRNA in the hypoxic and anoxic turtle brain, expressed as percent of normoxic control. Each experiment utilized five individuals per group. $\mathrm{N}=$ normoxia, $\mathrm{H}=4 \mathrm{~h}$ hypoxia, $1 \mathrm{~A}=1 \mathrm{~h}$ anoxia, $4 \mathrm{~A}=4 \mathrm{~h}$ anoxia, $\mathrm{R}=4 \mathrm{~h}$ anoxia $/ 4 \mathrm{~h}$ reoxygenation. Columns are numbered $1-5$. Column $1(\mathrm{~N})$ differs significantly from column $2(\mathrm{H}),(p<0.01)$; column $1(\mathrm{~N})$ differs significantly from column $4(4 \mathrm{~A}),(p<0.05)$; column $4(4 \mathrm{~A})$ differs significantly from column $5(\mathrm{R}),(p<0.01)$.

mRNA expression was seen with a 4.7-fold increase relative to normoxic control levels.

There are two distinct phases in anoxic responses in the turtle brain: the initial entry phase characterized by $\mathrm{K}_{\mathrm{ATP}}$ channel activation and downregulation of ATP consuming processes and a second long-term (h/days) maintenance of a deep hypometabolic state [29]. The purpose of this study was to establish whether neuroglobin mRNA expression was upregulated during the long-term maintenance phase, to compare anoxic mRNA expression levels with those obtained over the same duration $(4 \mathrm{~h})$ of hypoxia, and to establish whether any further upregulation occurred upon reoxygenation after anoxia. Previous studies have demonstrated that during $4 \mathrm{~h}$ anoxia and with anoxia followed by $4 \mathrm{~h}$ reoxygenation there is no alteration in either actin or HIF-1 transcripts confirming that there is no generalized transcriptional response to anoxia or anoxia plus reoxygenation [17].

\section{Discussion}

This is the first report of regulated expression of neuroglobin mRNA in response to altered oxygen availability in an anoxia-tolerant organism. The turtle brain affords us the unique opportunity to examine responses to oxygen deprivation in the absence of pathological processes associated with hypoxic responses in mammalian neurons. The upregulation of neuroglobin transcripts during anoxia and during hypoxia may reflect it's potential role as a hypoxia sensor, or may relate to an alternative function such as an intracellular oxygen carrier or a component in a detoxification pathway [23, 22, 24].

Any of these functions, however, would increase cell survival under hypoxic conditions. While the upregulation of $\mathrm{Ngb}$ by hypoxia and increased neuronal survival in vitro and in vivo has been reported [25, 27], other investigators, however, found no significant changes in $\mathrm{Ngb}$ levels in murine brains after chronic hypoxic $\left(\begin{array}{lll}10 \% & \mathrm{O}_{2}\end{array}\right)$ exposure [26]. As earlier work involved anoxic/ reperfusion and ischemic animal models [27], however, this difference may simply imply that $\mathrm{Ngb}$ is upregulated only under severely hypoxic/ anoxic conditions.

Until now the majority of biochemical studies on $\mathrm{Ngb}$ have been carried out on mammalian species. However, a comparative approach involving non-mammalian species offers a promising tool for the identification of conserved $\mathrm{Ngb}$ features and thus for the further understanding of $\mathrm{Ngb}$ function. The advantage of the turtle model is that in vivo experiments can be performed on severely 
hypoxic and anoxic animals, as they are able to survive and recover from long-term anoxia [for review, see 29]. In this study, $4 \mathrm{~h}$ hypoxia $\left(5 \% \mathrm{O}_{2}\right)$ resulted in a more than 3-fold induction of $\mathrm{Ngb}$ in the turtle brain, with an even larger increase upon reoxygenation following anoxia. Acute $(1 \mathrm{~h})$ and chronic $(4 \mathrm{~h})$ anoxia, however, resulted in a much smaller degree of induction, implying that the role or regulation of $\mathrm{Ngb}$ in the turtle brain is relatively specific to hypoxia, and that induction is not a rapid process in response to low oxygen levels. Blood gas analysis has demonstrated that blood oxygen levels have essentially reached 0 Torr by the end of the first hour anoxia in vivo [30], however until this time oxygen is present though decreasing. Any rapid, oxygen sensing response of $\mathrm{Ngb}$, then, should have also occurred during the first hour of anoxia in these experiments, however, Ngb mRNA only increased approximately $60 \%$ by $1 \mathrm{~h}$ anoxia, with a continued increase to $200 \%$ of basal by $4 \mathrm{~h}$ anoxia despite the complete absence of systemic oxygen.

In hypoxic rat brain, neuroglobin is induced by hypoxia either through HIF-1 signaling or potentially through non-HIF-1 mechanisms. In the rat these changes occur in the context of ongoing pathological neuronal damage. The induction of $\mathrm{Ngb}$ by hypoxia in mice, but not by pharmacological agents such as cobalt chloride or deferoxamine [25] suggests the specific regulation of $\mathrm{Ngb}$ through hypoxia signaling pathways (HIF-1- $\alpha$ ), though alternative regulatory pathways have also been suggested. A comparison of mouse and human Ngb genes, for example, did not show conserved hypoxia responsive elements (HREs) that would permit induction by HIF-1 [31]. While the magnitude of the hypoxic induction in the turtle brain was relatively large the induction in anoxia was more modest. This difference between hypoxic and anoxic responses in turtle brain may suggest either a distinct transcriptional regulatory mechanism or some additional signaling cross talk in the hypoxic state in the turtle brain. Indeed in mammals hypoxic induction of neuroglobin transcripts is induced via a MAP kinase pathway and different MAP kinases are renowned for demonstrating cross talk between each other as well as with other non-MAP kinase pathways [32].

The greater upregulation of $\mathrm{Ngb}$ in hypoxia and in anoxia/ reoxygenation, by comparison to anoxia, also implies a functional role in the presence of oxygen that is not required in anoxia (e.g. ROS detoxification vs. the anoxic regeneration of $\mathrm{NAD}^{+}$). As $T$. scripta depends upon metabolic suppression and anaerobic lactate production for anoxic survival, a role for $\mathrm{Ngb}$ in the regeneration of $\mathrm{NAD}^{+}$would be likely to be redundant. The absence of a strong upregulation of Ngb under conditions of no oxygen rather than when oxygen is present would also argue against a role for $\mathrm{Ngb}$ in the regeneration of $\mathrm{NAD}^{+}$.

As previously reported [21] the neuroprotective role of elevated $\mathrm{Ngb}$ expression could also be due to the degradation of ROS, though no study has yet verified this possibility. Neurons consume large amounts of oxygen, and are particularly vulnerable to ROS damage due to the abundance of unsaturated fatty acids, which propagate lipid peroxidation, and low ROS defenses [33]. The presence of Ngb in highly active tissues including fish gills [34], the retina [35] and endocrine tissues [36] could indicate roles in either ROS metabolism or oxygen delivery. The greater induction of $\mathrm{Ngb}$ by hypoxia over anoxia, and additional increases upon reoxygenation, may indicate a more likely role as an ROS scavenger in the turtle brain than as a means to increase oxygen delivery.

In conclusion, we have observed a major induction of neuroglobin gene expression in hypoxia and upon post-anoxic-reoxygenation in the brain of the anoxia-tolerant turtle. A smaller upregulation of neuroglobin gene expression was found during sustained anoxia. These observations point to a key protective role for neuroglobin in scavenging of reactive oxygen species under conditions of oxygen deprivation and upon reoxygenation.

\section{Acknowledgements}

This work was supported by the Florida Atlantic University Foundation, and the American Heart Association (Florida Affiliate). This is the contribution number P200523 from the Florida Center of Excellence in Biomedical and Marine Biotechnology.

\section{References}

1. Lutz P.L., Prentice H.M. and Nilsson G.E., The Brain without Oxygen, 3rd ed. Kluwers Press, Netherlands, 2003. 
2. Liu J., Narasimhan P., Yu F. and Chan P.H., Neuroprotection by hypoxic preconditioning involves oxidative stress-mediated expression of hypoxia-inducible factor and erythropoietin. Stroke 36(6), 1264-1269, 2005.

3. Date T., Mochizuki S., Belanger A.J., Yamakawa M., Luo Z., Vincent K.A., Cheng S.H., Gregory R.J. and Jiang C., Expression of constitutively stable hybrid hypoxia-inducible factor-lalpha protects cultured rat cardiomyocytes against simulated ischemia-reperfusion injury. Am. J. Physiol. Cell Physiol. 288(2), C314-C320, 2005.

4. Alsbury S., Papageorgiou K. and Latchman D.S., Heat shock proteins can protect aged human and rodent cells from different stressful stimuli. Mech. Ageing Dev. 125(3), 201-209, 2004.

5. Yamada K. and Inagaki N., Neuroprotection by KATP channels. J. Mol. Cell Cardiol. 38(6), 945-949, 2005.

6. Zhao P., Qian H. and Xia Y., GABA and glycine are protective to mature but toxic to immature rat cortical neurons under hypoxia. Eur. J. Neurosci. 22(2), 289-300, 2005.

7. Germack R. and Dickenson J.M., Adenosine triggers preconditioning through $\mathrm{MEK} / \mathrm{ERK} 1 / 2$ signalling pathway during hypoxia/reoxygenation in neonatal rat cardiomyocytes. J. Mol. Cell Cardiol. 39(3), 429-442, 2005.

8. Tomaselli B., Podhraski V., Heftberger V., Bock G. and Baier-Bitterlich G., Purine nucleoside-mediated protection of chemical hypoxia-induced neuronal injuries involves p42/44 MAPK activation. Neurochem. Int. 46(7), 513-521, 2005.

9. Jackson D.C., Living without oxygen: lessons from the freshwater turtle. Comp. Biochem. Physiol. A 125(3), 299-315, 2000.

10. Milton S.L. and Lutz P.L., Low extracellular dopamine levels are maintained in the anoxic turtle brain. J. Cereb. Blood Flow Metab. 18: 803-807, 1998.

11. Milton S.L., Thompson J.W. and Lutz P.L., Mechanisms for maintaining extracellular glutamate levels in the anoxic turtle striatum. J. Appl. Physiol. 282: R1317-R1323, 2002.

12. Nilsson G.N. and Lutz P.L., Adenosine release in the anoxic turtle brain: a possible mechanism for anoxic survival. J. Exp. Biol. 162: 345-351, 1992.

13. Nilsson G.N. and Lutz P.L., Release of inhibitory neurotransmitters in response to anoxia in turtle brain. Am. J. Physiol. Reg. Integr. Comp. Physiol. 261: R32-R37, 1991.

14. Fernandes J.A., Lutz P.L., Tannenbaum A., Todorov A.T., Liebovitch L. and Vertes R., Electroencephalogram activity in the anoxic turtle brain. Am. J. Physiol. 273: R 911-R919, 1997.

15. Greenway S.C. and Storey K.B., Mitogen-activated protein kinases and anoxic tolerance in turtles. J. Exp. Zool. 287(7), 477-484, 2000.

16. Prentice H.M., Milton S.L., Scheurle D. and Lutz P.L., The upregulation of cognate and inducible heat shock proteins in the anoxic turtle brain. J. Cereb. Blood Flow Metab. 24: 826-828, 2004.

17. Prentice H.M., Milton S.L., Scheurle D. and Lutz P.L., Gene transcription of brain voltage-gated potassium channels is reversibly regulated by oxygen supply. Am. J. Physiol. Regul. Integr. Comp. Physiol. 285(6), R1317-R1321, 2003.

18. Belkin D.A., Anoxia: tolerance in reptiles. Science 139: 492-493, 1963.

19. Nilsson G.N., Lutz P.L. and Jackson T.L., Neurotransmitters and anoxic survival in the brain: A comparison of anoxia-tolerant and anoxia-intolerant vertebrates. Physiol. Zool. 64(3), 638-652, 1991.

20. Burmester T., Weich B., Reinhardt S. and Hankeln T., A vertebrate globin expressed in the brain. Nature 407: 520-523, 2000.

21. Burmester T. and Hankeln T., Neuroglobin: A respiratory protein of the nervous system. News Physiol. Sci. 19: 110-113, 2004.

22. Sowa A.W., Duff S.M.G., Guy P.A. and Hill R.D., Altering hemoglobin levels changes energy status in maize cells under hypoxia. PNAS 95: 10317-10321, 1998.

23. Herold S., Fago A., Weber R.E., Dewilde S. and Moens L., Reactivity studies of the $\mathrm{Fe}(\mathrm{III})$ and $\mathrm{Fe}(\mathrm{II}) \mathrm{NO}$ forms of human neuroglobin reveal a potential role against oxidative stress. J. Biol. Chem. 279: 22841-22847, 2004.

24. Kriegl J.M., Bhattacharyya A.J., Nienhaus K., Deng P., Minkow O. and Nienhaus G.U., Ligand binding and protein dynamics in neuroglobin. PNAS 99: 7992-7997, 2002.

25. Sun Y., Jin K., Mao X.O., Zhu Y. and Greenberg D.A., Neuroglobin is upregulated by and protects neurons from hypoxic-ischemic injury. PNAS USA 98: 15306-15311, 2001.

26. Mammem P.P.A., Shelton J.M., Goetsch S.C., Williams S.C., Richardson J.A., Garry M.G. and Garry D.J., Neuroglobin, a novel member of the globin family, is expressed in focal regions of the brain. J. Histochem. Cytochem. 50(12), 1591-1598, 2002.

27. Sun Y., Jin K., Peel A., Mao X.O., Xie L. and Greenberg D.A., Neuroglobin protects the brain from experimental stroke in vivo. PNAS USA 100: 3497-3500, 2003.

28. Bickler P.E. and Donohoe P.H., Adaptive responses of vertebrate neurons to hypoxia. J. Exp. Biol. 205(Pt 23), 3579-3586, 2002.

29. Lutz P.L. and Milton S.L., Negotiating brain anoxia survival in the turtle. J. Exp. Biol. 207: 3141-3147, 2004.

30. Milton, S.L., The physiology of hypoxia and anoxia tolerance in three species of turtle: the loggerhead sea turtle (Caretta caretta), green sea turtle (Chelonia mydas) and freshwater Trachemys scripta. Ph.D. Thesis, University of Miami, 1994, pp 196.

31. Wystub S., Laufs T., Schmidt M., Burmester T., Maas U., Saaler-Reinhardt S., Hankeln T. and Reuss S., Localization of neuroglobin protein in the mouse brain. Neurosci. Lett. 346: 114-116, 2003.

32. Zhu Y., Sun Y., Kunlin J. and Greenberg D.A., Hemin induces neuroglobin expression in neural cells. Blood 100: 2494-2498, 2002.

33. Evans P.H., Free radicals in brain metabolism and pathology. Br. Med. Bull. 49: 577-587, 1993.

34. Fuchs C., Heibs V., Kiger L., Haberkamp M., Roesner A., Schmidt M., Hamdane D., Marden M.C., Hankeln T. and Burmester T., Zebrafish reveals different and conserved features of vertebrate neuroglobin gene structure, expression pattern, and ligand binding. J. Biol. Chem. 279: 24116-24122, 2004

35. Schmidt M., Giel A., Laufs T., Hankeln T., Wolfrum U. and Burmester T., How does the eye breathe? Evidence for neuroglobin-mediated oxygen supply of the mammalian retina. J. Biol. Chem. 278: 1932-1935, 2003.

36. Reuss S., Saaler-Reinhardt S., Weich B., Wystub S., Reuss M., Burmester T. and Hankeln T., Expression analysis of neuroglobin mRNA in rodent tissues. Neuroscience 115: 645-656, 2002. 